\title{
Italian-Americans' Contested Whiteness in Early Cinematic Melodrama
}

\author{
VALERIO COLADONATO, Sapienza University of Rome
}

\begin{abstract}
The concept of 'whiteness' has acquired a central role in race studies. The historical process through which the Italian-American community became 'white' is a relevant case study for showing the constructedness of this category and the power relations that underpin it. This paper focuses on the role played by early cinematic melodrama in light of wider social and political transformations that led to the assimilation of Italian immigrants into American racial discourse. In early twentieth-century United States, mass immigration and the institutionalisation of cinema were two inter-related phenomena. Cinema became a 'respectable' medium by assigning itself a moral and didactic role. Attending film screenings was, for millions of immigrants, a way to become 'Americanised'. In the same period, wider socio-political discourses contributed to the re-signification of 'whiteness' in American society. In order to accommodate both the need of cheap immigrant labour and nativist ideologies concerned with the purity of the 'white' (e.g. Anglo-American) core of society, 'whiteness' became fragmented into an array of racially inflected 'national types'. Among them, Italian-Americans were only provided with 'probationary whiteness', and were still deemed as racially inferior and 'unfit for self-government'. US cinema deployed melodramatic narratives to negotiate the 'white' status of Italian-Americans through the polarised moral discourse that characterised this particular genre. It is possible to trace different stylistic paradigms of early American cinema by comparing several melodramas directed by D.W. Griffith and later movies, such as Reginald Barker's The Italian (1915). The representations of Italian-Americans as Others in cinematic melodrama, and their subsequent assimilation into dominant racial ideology, reveals the variable and complex meanings of the social category of whiteness.
\end{abstract}

\section{KEYWORDS}

Whiteness; Italian-Americans; Early cinema; Melodrama; Race; David W. Griffith; Immigrants

\section{Introduction}

The concept of 'whiteness' has acquired a central role in race studies (Wiegman 1999). This category allows us to deconstruct the ways in which hegemonic positions are established and maintained in racial discourse. The critical scrutiny of how privileged groups acquire their status through complex representational strategies is a fundamental step to place race within the domain of history, sociology and politics. This is part of the attempt to unveil racist ideologies.

The historical process through which the community of Italian-Americans became 'white' in the first decades of the twentieth century is a relevant case study for showing the social processes that underlie race and the power relations that underpin it (Guglielmo and Salerno 
2003). One way to approach this transition is to focus on media representation and reception. This paper discusses the role played by early cinematic melodrama in the light of the wider social and political transformations that led to the assimilation of Italian immigrants into American racial dominant discourse.

First, I briefly consider the historical background and the ideologies that contributed to the definitions of whiteness in this particular context. Then, I elaborate on the role of cinema in shaping specific subjectivities for Italian-Americans. I highlight how the transformations in film style converge with new possibilities for the Italian-American audience to identify with characters, and to negotiate their racial status as immigrants. Without positing a direct and systematic relation between these two aspects, I rather point at the complex ways in which they intertwine.

\section{Whiteness and Italian immigrants in early twentieth-century US}

According to Jacobson (1998), the history of European immigrants in the US can shed some light on how race is socially constructed. Mass immigration to the US was made possible by the definition included in the 1790 Naturalization Law, which stated that candidates need only be 'free white persons'. In the formulations of this period, racial discourse was supported by the ideology of 'fitness for self-government'. This principle survived into the twentieth century, as it is clearly stated in the words of a judge who, in 1921, opposed the right to citizenship for Asian immigrants: 'the objection [...] is not due to colour, as colour, but only to colour as an evidence of a type of civilization which it characterizes' (Jacobson 1998, 224). In the case of Europeans, 'it was their whiteness, not any kind of New World magnanimity, that opened the Golden Door' (Jacobson 1998, 8).

The arrival of millions of immigrants at the beginning of the century brought some contradictions between capitalism and racial ideology to the fore, with a constant tension 'between the necessity of huge numbers of immigrants as labourers on the one hand, and the menace posed by these same immigrants as ill-equipped citizens on the other' (Jacobson 1998, 72). The condition of whiteness that was attributed to Europeans continued to guarantee their access to the US territory, but it was no longer a proof of their adhesion to the civil and political principles of the nation. What took place was a fragmentation of whiteness and the creation of an internal hierarchy. This is a remarkable example of the instability of racial categories: race is a construct, or a 'floating signifier' (in Hall's definition, 1992) which varies over time, adjusting itself to different ideological needs. Some groups, such as the Italians, began to be considered at once white (therefore 'superior' to African-Americans and Other 'coloured' groups) and racially 'inferior' to Anglo-Americans. Italian-Americans were, in fact, assigned a sort of 'probationary whiteness'. As explained by Gabaccia (2003), in the new political discourse 'social Darwinism rooted consensual citizenship not just in whiteness (as it had been since 1790), but in the Anglo-Saxon race, thus segmenting the nation into those racially more and less fit for citizenship' (57).

By reviewing how the ideas of citizenship and race were intertwined, I intend to underline an aspect that has, at times, been overlooked. Early cinema played a fundamental part in 'Americanising' immigrant audiences. This is a widely documented phenomenon (Mayne 1988; Uricchio 1999). We must remember, however, that, given the political conceptions prevalent at the time, any discourse on Americanisation was also inevitably a discourse on race. How did cinema, then, contribute to the circulation of ideas on whiteness? It is important to consider that, very often, a 'white' status was not an integral part of how 
immigrants perceived themselves on arrival. Rather, this was negotiated over time through multiple interactions with American society. As Baldwin (1984) succinctly puts it, "no one was white before he/she came to America. It took generations, and a vast amount of coercion, before this became a white country' (1).

Whiteness has been defined, in the first place, in a dialectic opposition to the AfricanAmerican experience. The history of slavery and racial segregation determined how the 'colour line' was drawn in the US: the exploitation of physical labour, together with the systematic deprivation of freedom and the rights to education, private property and political participation, marked American society long after the end of segregation. 'Blackness' has often been the condition from which other racial groups have tried to distance themselves (Hollinger 2005). Just a few decades after the end of slavery, Italians arriving in the US learned that 'to be white meant having the ability to avoid many forms of violence and humiliation, and assured preferential access to citizenship, property, satisfying work, liveable wages, decent housing, political power, social status, and a good education, among other privileges' (Guglielmo 2003, 3).

As Wiegman (1999) points out in her reconstruction of whiteness studies, this academic field has often focused on the process of transition to whiteness. The social groups who became white gained access to the entailed privileges while, at the same time, accepting the implications of racist oppression. From this perspective, the concept of wage -to be interpreted in racial, and not merely economic terms- has been a crucial one. These groups were still economically oppressed but, being granted 'whiteness', they perceived themselves as hierarchically 'superior' to African-Americans: 'whiteness emerges as the compensatory psychological and public "wage" that enabled various groups, especially the Irish - often called the "black Irish" - to negotiate a social status simultaneously distinct from and opposed to that of the slave or ex-slave' (Wiegman 1999, 122). The category of 'wage' is present in the works of W.E.B. du Bois, and it has been developed most extensively by Roediger (1991). The identification with the interests of race, rather than those of class, has severely undermined the struggles of the white American working class. Other influential scholars also stress the factor of economic inequality. According to Omi and Winant (2008), for example, racial formation is constantly sustained by the need of capitalism to exploit differences.

Why do we focus on race, rather than ethnicity, when considering the community of ItalianAmerican immigrants? Nativist ideologies played an important part in the Othering of these new groups. Anti-Catholic sentiment, for instance, was one of the factors that served to Other Italians and the Irish. For a long time, scholars have considered Europeans who migrated to the US around the turn of the twentieth century as being part of 'ethnic' groups. However, in doing so, they have applied a category that was developed only later, mainly in the 1920s and 1930s. As Jacobson (1998) convincingly argues, in the years that we are taking into account, people "recognised biologically-based "races" rather than culturally-based "ethnicities" (6). Just as human bodies are assigned an unequivocal gender identity by the dominant ideology (Butler 1990), racial identity was also conceived in exclusive terms. Italian-Americans' racial difference was progressively erased after the Immigration Act of 1924. This law introduced further restrictions to immigration, leading to a new polarisation of racial discourse between black and white. It is only in this new discursive framework that most European immigrants were definitively granted unconditional whiteness, by virtue of their inclusion within the more comprehensive category of the Caucasian race (Jacobson 1998, 201-246). 


\section{Cinematic whiteness: Visual strategies and 'gaze theory'}

The issue of whiteness and visual representation in the cinema has been addressed following two main approaches. On the one hand, scholars have discussed how certain representations racialise characters by using specific strategies that translate racial categories in visual terms (mostly lighting and make-up, but also specific acting styles). On the other hand, there have been attempts to include the factor of race within the 'gaze theory' of cinema (Kaplan 1997) in order to understand how racial identification influences the articulation of the spectatorial gaze, and the relation between the audience and the characters on the screen.

As for the first approach, Dyer (1997) analyses the way in which white people have visually portrayed themselves in cinema, photography, painting, and other visual media. His goal is to make whiteness evident and readable as a social construct, by bringing to the fore the ways in which white people are treated as a 'human norm' (1), apparently not belonging to a specific race. Dyer shows how racism reduces non-white subjects to a function of white discourse (13). The attribution of racial categories is a matter of power, and there is no greater power than defining the norm against which Otherness is established and measured. It is this faculty that white people have historically claimed for themselves: the possibility to look without being looked at. The code of colour in racial categories is particularly telling: the skin of no human being is literally white, and the attribution of this neutral and 'empty' colour to certain groups is used to secure for them a condition of structural invisibility, from which Other groups are excluded (Dyer 1997, 42). Nevertheless, this invisibility can never be fully reached because white, though neutral, is still a colour. Therefore, 'to apply the colour white to white people is to ascribe a visible property to a group that thrives also on invisibility' (42). The normative position, then, contains within itself an inescapable tension: the value of whiteness, universal and particular at once, makes this normative position unstable and contradictory.

This instability is not limited to racial categories, but is constitutive of all identities. For instance, Butler (1990) argues that the fluidity of gender identities can be actively used in the struggle for equality and the establishment of anti-discriminatory policies. However, the instability of racial categories has also been used to perpetuate inequalities. Whiteness has been constructed through a particularly effective paradox. On the one hand, it is based on a long-standing dichotomy, opposing whites and non-whites (blacks in particular). This was exemplified by the 'one drop' rule, according to which a single African-American ancestor determines the black identity of a person (Hollinger 2005). On the other hand, in some contexts 'a category of maybe, sometimes white' is created for 'people who may be let into whiteness under particular historical circumstances' (Dyer 1997, 19). Millions have therefore aspired to become part of this group:

Because whiteness carries such rewards and privileges, the sense of a border that might be crossed and a hierarchy that might be climbed has produced a dynamic that has enthralled people who have had any chance to participate in it. [...] Whiteness has been enormously, often terrifyingly effective in unifying coalitions of disparate groups of people (Dyer 1997, 19-20).

Regarding the production of images, Dyer reminds us that light-based technologies, such as photography, are not neutral, and they have historically played an important role in supporting racial categorisations. The vast majority of photography handbooks, in describing the combinations that lead to the correct exposure of a human face, are based on the 
assumption that a 'normal' face is a 'white' one. A similar observation can be made of the film industry, where the techniques and features of lighting styles have been developed with similar principles (Dyer 1997, 82-144).

In cinema, the whiteness of characters is not only coded in visual terms, but it is also established through inter-subjective dynamics that regulate the gaze between audience and characters, and among the characters themselves. Therefore, the second approach that I consider here is that of 'gaze theory'. Gaines (1986) argues that exclusive attention to gender had limited the ability of cinematic gaze theory to account for different scenarios of identification and desire, especially when race is at play. She recalls, in particular, that the central role of psychoanalysis in gaze theory is likely to make this approach ineffective with regards to the African-American experience:

The Freudian scenario, based on the male/female distinction, is incongruous with the scenario of racial and sexual relations in Afro-American history. Where we use a psychoanalytic model to explain Black family relations, we force an erroneous universalization, and inadvertently reaffirm white middle-class norms (1986, 61).

Kaplan (1997) provides an indirect answer to this quandary. She makes the case for a historically-specific use of psychoanalysis within a wider exploration of cinema and the construction of Otherness. With a diverse array of examples, Kaplan analyses films dealing not only with racial relations in the US, but more generally with Western imperialism and colonialism. She argues that "the "male" gaze and the "imperial" gaze cannot be separated within Western patriarchal cultures' (Kaplan 1997, xi). Similarly to how Laura Mulvey (1975) described the masculinisation of the spectatorial position, Kaplan maintains that 'Western spectators' eyes have been "imperialized" throughout the history of Hollywood cinema' $(1997,19)$. It is possible to trace a series of analogies between race and gender 'with similar ideological patterns of objectification, exclusion and "othering"" (15). With regards to race, many Hollywood images treat racial minorities as childish, beast-like, libidinous and immoral. This last point is particularly relevant to my argument, since many films have represented 'minorities as immoral, not knowing right from wrong, if not quite simply evil' (80).

This intersectional model, which deals with both gender and race, is effective because it does not account for these dynamics in exclusive terms. Rather, it emphasises how different oppressive structures interact with each other. Furthermore, this model invites us to look at race in flexible and historically-specific ways. The focus is not on race as the marker of a fixed identity, but on how the process of racialisation takes place in a given context. Capitalism, racism and patriarchy (all of which usually work together seamlessly) at times interfere with each other in problematic ways, therefore leaving room for resistance and subversion. Some of these cases have already been explored in film studies. For example, in her pioneering work, Hansen (1991) shows how patriarchal ideology was temporarily set aside in the star cult surrounding Rudolph Valentino. The commercial needs of the film industry in promoting a star that would mobilise women's desire prevailed, giving way to an exceptional challenge to traditional gender roles. In other instances, capitalism overcomes racist ideologies, as it happened with sponsored movies like An American in the Making (Carl L. Gregory 1913), which opposed restrictions to immigration in order to maintain a wide number of low-wage workers coming to the US. These films reduced the emphasis on racial differences and supported assimilation into the new society in specific situations. The opposite dynamic can also be observed. This is the case of the so-called 'race movies', which 
were directed, interpreted and watched by African-Americans. Gaines (2001) argues that such films were based on 'the oddity of black capitalism, its success based on a lapse in a white capitalism that would for a limited time forsake its imperative to expand in order to better serve the ideology of racial superiority' (14). As these examples show, a historicallygrounded intersectional model presents an important opportunity, as it brings to the fore those junctures in which competing ideologies momentarily clash with one another and oppressive structures can be thwarted, opposed and modified. This theoretical model allows for a more effective contribution of scholarship to anti-discriminatory struggles.

\section{Italian-Americans: between spectatorship and representations}

How did these competing forces and ideologies concretely shape the relation between ItalianAmericans and the cinematic screen in the early years of the new medium? After discussing some general aspects of immigrant spectatorship, I will focus on five melodramas portraying Italian-American characters: four of them were directed by David Wark Griffith, whose highly problematic relationship with racism has already been at the centre of critical scrutiny (Stokes 2007); the fifth example (The Italian, directed by George Beban) will help to point out how the transitions in film styles have affected the representation of race. Given the scope of the article, I will not analyse the films in their entirety, but I provide a description of some specific aspects and scenes.

Like immigrants of many other nationalities, Italian-Americans soon crowded cinema shows in the early years of the twentieth century, becoming a considerable part of the nickelodeon audience. Attending the cinema was a moment of resistance to alienating living conditions, as it both permitted immigrants to temporarily participate in an 'alternative public sphere' (Hansen 1991) and to enjoy the often inaccessible world of leisure and consumption. A fundamental aspect in cinema-going was the opportunity for immigrant women to experience something different from the household and the workplace (Muscio 2004, 30). As Hansen (1991) writes, 'for young Italian women [...] going to the movies several times a week was often the only unsupervised leisure activity they were permitted and could afford' (118). The strong presence of female spectators was a source of anxiety for a community with strong patriarchal values. An Italian-American commentator invited 'fathers not to complain if, when allowing their daughters (li figghi fimmini) to have fun at the movie shows, they returned home with new knowledge (ammaistrati)' (Bertellini 2004, 65).

For all immigrants, cinema was a mediation between their experiences in the homeland and the ones in the New World. As separate spaces for the negotiation of social roles with other groups, the nickelodeons became important sites of redefinition of the public and private spheres. For the Italian-American community, the first screenings took place in caféchantants, which had already been hosting dialectal theatre, musical and variety shows for several years (Bertellini 2004). Thus, films became part of an already established tradition of live shows, characterised by continuous interaction between spectators and performers, and by the openness of narrative structures. Whereas in such screenings the collective dimension of spectatorship remained fundamental, the later transition to a more individual mode of reception had a strong ideological significance: it was a metaphor of the assimilation into American society, and its promises of material well-being under capitalism (Mayne 1988). Taking into account such early experiences of cinema spectatorship among immigrants, we can 'subvert the broad (and teleologically defined) presumption that the development of the American film industry meant a quick and inevitable process of acculturation of nonAmerican communities' (Bertellini 2004, 42). 
It is within this process of negotiation of new identities that we must consider how ItalianAmericans were portrayed in early cinema. In these years, Italian-Americans are predominantly characterised as criminals: they appear as uncivilised and 'naturally' inclined to revenge and violence. When discussing the films, I will examine the relation between these persistent stereotypes and Italian immigrants' racial positioning. In nativist discourse, Italians could not be considered equivalent to Anglo-Americans. Nevertheless, their skin colour was not enough to justify such 'inferiority': they were considered white, as all Europeans. This ideological contradiction was solved by emphasising the close relation between whiteness and citizenship: if Italians could not be categorised as non-white because of their skin, they could still be treated as racially different if it was proved that they were unfit citizens. As Bertellini (2009) writes, regarding Italian-American characters in early cinema,

A frequently recurring means of racial underscoring was the law, with its sets of policies and regulations defining a social contract that Italians were depicted as naturally breaching. [...] This racial dissonance signified the unlikelihood of their full equivalency with native white characters (184).

In his compelling book, Bertellini discusses films such as The Black Hand (1906), which gave great visibility to the myths surrounding Italian-Americans' criminal organisations. According to Bertellini, there were also some attempts to provide a positive model for Italian immigrants and their relation with the law. This is the case, for instance, of a series of films dedicated to real-life policeman Joe Petrosino. However, the way in which the character is portrayed in The Adventures of Lieutenant Petrosino (Sidney Goldin 1912) reveals some ambiguities. In particular, the complete absence of close-ups discourages identification with the protagonist. The difference with The Italian (1915), which I will discuss below in further detail, is remarkable. Produced only a few years later, The Italian presents plenty of close-ups of the Italian protagonist, who is a fully-rounded character with whom it is possible to identify. Bertellini (2009) argues that The Adventures of Lieutenant Petrosino 'never contradicts the audience's memory of [Petrosino's] appearance with close-ups of the actor playing him' (202). The film, then, aims at maintaining an impression of 'realism' but, at the same time, it deploys the whole repertoire of stereotypes associated to Italian-American criminals, who are portrayed as a horde of violent, gesticulating savages, not distinguishable from one another.

How do these apparently contradictory strategies - 'realism' and stereotypes - work together? It is useful to recall what Homi Bhabha (1994) argues regarding the discursive economy of colonialism. Colonial discourse "employs a system of representation, a regime of truth, that is structurally similar to Realism', and has the objective 'to construe the colonised as a population of degenerate types on the basis of racial origin' (23). The use of stereotypes as a fetish is central in this discursive system because it allows, for both colonisers and colonised, multiple and contradictory beliefs about their own identity, giving way to split subjectivities. Besides, in such discourse the colonised population does not have access to the position of subject. This population is rhetorically addressed as a collective, not as a series of welldefined and diverse individuals. My argument is that, although the social and historical context is not properly that of colonialism, in these films we find a somewhat similar mechanism.

The Adventures of Lieutenant Petrosino, then, presents a clear-cut split between the 'good' Italian policeman Petrosino and the 'evil' Italian criminals he fights against. In this and other 
films, the obsessive repetition of stereotypes intertwines with the binary dualism of melodramatic narratives. As Singer (2001) writes in his influential discussion of early melodramatic forms in cinema, 'melodrama's worldview is simplified; everyone's ethical status is immediately readable' (23). Such strong moral polarisation between good and evil is extremely recurrent in the films of the period, especially those portraying immigrant characters. Singer relates this feature to the social context and, in particular, to the transformations induced by urban modernity. He interprets the success of the melodramatic genres as:

a symptomatic response to a new condition of moral ambiguity and individual vulnerability following the erosion of religious and patriarchal traditions and the emergence of rampant cultural discontinuity, ideological flux, and competitive individualism within capitalist modernity $(2001,46)$.

Within a fast-changing society and the collapse of all moral certainties, cinema audiences could find some respite on the screen, where good and evil could still be identified without hesitation.

\section{From Griffith's melodramas to Barker's The Italian}

Let us consider the representations of Italian-American characters in four single-reel movies from the Biograph period of David Wark Griffith's production (At the Altar, In Little Italy and The Cord of Life, all dating 1909; and The Coming of Angelo 1913), and in the feature film directed by Reginald Barker, The Italian (1915). These films all share two main features: in the first place, the racialisation of Italian characters; secondly, a narrative structure influenced by melodramatic patterns, in which the peacefulness of a domestic idyll is disrupted by an external threat. Additionally, they are distributed along a short span of time, in which the transformation of American film style is particularly evident: they are caught in the transition between the early attractions system, and what would later come to be known as the 'classical' Hollywood style. By comparing them together, it is possible to highlight how this transition affected characters' representations and, in the case of Italian-Americans, also allowed for the emergence of new subjectivities.

The three films of 1909 share further similarities. They all include the following narrative points: a prologue set around the table in an Italian-American household; the presentation of a conflict (either related to love or money); a character who sets up a revenge scheme; the desperate effort to rout the evil plan; and the re-establishment of the initial serenity. Carluccio (1999) points out that this type of plot is

obsessively repeated in the early Griffith films. An external character threatens the life of a woman or a child (almost always the wife or daughter within the family) until order is restored [...] with a man (father, husband or lover) recuperating his position of property (265).

Moreover, the narratives clearly present the two-fold connotation of the melodramatic genre which, as described by Singer (2001), are both dystopian ('portraying worst-case scenarios of the victimization of innocents') and utopian ('offering a comforting affirmation of moral oversight and inevitable poetic justice') (Carluccio 1999, 294).

At the Altar is a short tale of sentimental revenge. The plot is minimal, and the thrill of the 
film relies, above all, on moments of 'attractions' and on the intense emotions provoked by situations of potential violence and physical danger. The first shot of At the Altar presents seven characters around a table. The composition of the image does not clearly indicate which of them will have a prominent role in the following events. A man to the left of the frame is frantically swallowing some spaghetti, in a way that brings to mind the 'ethnographic' photographs taken in the Italian neighbourhoods of the same era (Bertellini 2009). Further contributing to the Otherness of the scene is the way in which the revenge plan is presented to the audience. The criminal stands up and literally acts out his plan, performing in front of the camera the gestures and violent actions he intends to carry out in the future. Without editing cuts or captions, the task is exclusively fulfilled by the actor's gestures and emotionally 'excessive' performance. This does not mean that he is presented as a subject, as the audience has no means to relate to his motivations or feelings. In At the Altar, the camera is kept far away at all times and characters appear as if they were on a stage, with their full bodies visible, but very little attention is given to their facial expressions. It is remarkable that the only close-up shot in the film singles out an object (the gun inserted in the trap below the altar) and not a character. Such traps were very common in the films of those years, and they created 'intricate death-delaying contraptions used to prolong suspense' (Singer 2001, 195). As Carluccio (1999) writes, in At the Altar 'the diegetic attraction of the deathly trap [...] is doubled by the attraction of the close up'; notwithstanding, the shot is 'logically inserted in the editing sequence, and it fits completely in the continuity of the revengeful Italian character's action' (172). The unresolved tension between attraction and narration is precisely what characterises this period of American cinema (Keil 2001). Here, the balance leans towards the attraction itself: what matters most is the shock that the deathly trap will provoke in the audience, while the introspection of the character remains largely unexplored.

In Little Italy also presents the stereotypical iconography of Italian criminals, consisting of a pronounced moustache and a handkerchief around the neck. In a more elaborate way, the film utilises a specific space, the bar, to single out the evil character. In this bar, the Italian man gets drunk and starts gesturing in a grotesque and beast-like manner. The caption associated to these gestures ('the unsuccessful suitor, crazed by jealousy, resolves to be revenged') contains two of the key features in the definition of Italian racial types. Jealousy and revenge, closely inter-related, emerge in almost every film of the period featuring Italian immigrants. As in the previous film, the violent outburst is meant to take place during a public ceremony: this time, the avenger intends to act during a ball. In the scene of the murder, the dance choreography acts as a delaying mechanism. The suspense of the scene is created by the fact that the audience already knows that there is going to be an attempted murder, while the victim remains unaware. Nevertheless, violence is not given dramatic emphasis by the use of close-ups so, when the stabbing takes place, the camera remains far away. The murderer's gesture is only readable thanks to the other characters' reactions. However, even these reactions are not individualised: the general astonishment resembles the prosecution of a collective choreography, rather than the reaction of single, distinguishable characters.

The delay of a decisive moment in the narrative is a mechanism that Griffith deployed with growing frequency during those early years (Keil 2001, 76). It is also present in The Cord of Life, where it appears in combination with cross-cutting. In this film, an Italian bandit decides to seek revenge for the wrongs he has received from another immigrant family, possibly because they refused to pay their debts. The plan consists of hanging the family's little son in a basket outside the window, so that the parents will inadvertently make him fall down to the street. The final sequence alternates shots of the mother (who, unaware of the trap, is about to cause her child's death) and of the father (who, like the audience members, knows what is 
about to happen and runs home to prevent it). Also in The Cord of Life, the blackmailer anticipates his sadistic plan by performing it for the camera with eloquent gestures and expressions, and clearly taking pleasure in this. Emotional 'excess' is also registered in his clothing, as the gangster's shirt is open and ruffled, the tie is loose, and the bottom of the trousers is stuck inside his boots. As in the two previous films, there are no close-up shots of the actors' faces to provide insights into the characters' psychology. Rather, the moments in which actors get closer to the camera correspond to their entrance or exit from the pro-filmic space. The human figure, therefore, is either relatively far away or confined to the margins of the frame (Carluccio 1999, 252).

Overall, these three films directed by Griffith in 1909 portray Italian-Americans as dominated by uncontrollable passions, as opposed to the emotional restraint of the ideal white subject. The themes of revenge, violence and criminality also signal their failed assimilation of the laws of American society, hence their subordinate racial status. Besides, the lack of subjective shots, close-ups and captions underscore their Otherness to the audiences.

Only four years later, Griffith's The Coming of Angelo presents several significant differences. As in At the Altar, the plot is based on a love triangle. This time, however, the three protagonists are named thanks to a more systematic use of captions: Theresa, her suitor Guido, and the man who takes her away from him, Angelo. We find, again, a detail of the deathly trap, which, on this occasion, consists of a ticking bomb, although its presence is more integrated within the narration than in previous films. As Keil (2001) puts it, 'because storytelling becomes uppermost in filmmakers' minds, the residual lure of the attraction finds itself more fully contained within a narrative context' (8). A caption gives us precise information on the consequences of the device ('another half-hour to live'), thus establishing a fixed deadline and making it an integral part of the narrative structure. In visual terms, this closer shot is no longer an exception in the film (Carluccio 1999, 81), as it is part of a wider series of details which include close-ups of a flower and a picture of Theresa. Generally, The Coming of Angelo presents a broader range of distances between the pro-filmic and the camera, from extreme close-ups to a long shot portraying Guido and Theresa along the beach. This allows for a more complex dynamic of looks. For instance, the shot on the beach is, in fact, a subjective view from the standpoint of Angelo, who is observing the two lovers from afar. However, a match on the same visual axis leads to a medium shot which is, in turn, an 'objective' look, as Angelo will soon enter the frame. The use of both 'subjective' and 'objective' shots is crucial among the techniques that were developed in order to foster audiences' identification with the characters.

As typical characteristics of the later years in the transition period, the average shot length is shorter and the general pace of the film is quicker. Therefore, with the same duration of the previous films, The coming of Angelo has a more elaborate distribution of narrative spaces, which amount to four: Theresa's house, Guido's house, the beach, and the road. This is in accordance with the goals that the industry and the directors were pursuing at the time: 'achieving verisimilitude, maintaining narrative legibility, and clarifying spatial and temporal relations' (Keil 2001, 127). The use of captions to clarify obscure passages, the variations in shot scale and editing techniques, such as cross-cutting, make the narrative easier to follow. At the same time, the adoption of 'classical' strategies provides the opportunity for some psychological introspection, both with regard to characters' motivations and to their emotional reactions. The focus on the wind and the rough water, for instance, seem to translate the inner turmoil of Theresa, who does not want to abandon Guido unfairly, and the latter's own emotions after finding out the lover's betrayal. The result is that, even if in The 
Coming of Angelo the themes of revenge and passion remain central, the physical and psychological traits of Italian-Americans are less unrefined and beast-like. The possibility of sharing the characters' points of view, as well as their emotions, creates the conditions for spectatorial identification. Discussing Griffith's films, Carluccio (1999) describes the

need for 'naturalism' in acting, which leads to condemn conventional gesturing of melodramatic derivation, for the sake of a more contained expressivity. [This acting style] utilises a more balanced facial expression - and therefore requires a closer positioning of the camera (80).

A fundamental aspect of the transition between the films discussed above and the ones produced in the early 1910s is, in fact, a remarkable shift in acting style. The more theatrical gesturing of the earlier years gives way to a 'naturalist' approach. This does not mean, however, that one style simply replaces the other. The two styles co-exist in the same period and, at times, even in the same film. Following the definition given by Pearson (1992), Keil (2001) describes the two styles as 'histrionic' and 'verisimilar'. Keil notes that they can be used by the same actor to convey racial differentiation: in interpreting 'native American, Italian or Mexican characters', an actor might use a histrionic style; whereas for AngloAmerican characters, he might use the 'verisimilar style' (153).

A clear example of this is Reginald Barker's The Italian (1915). The main actor, George Beban, had already starred in other melodramas concerning the difficulties of immigrants in the New World and, in his 'impersonations', he often resorted to different styles of acting. Bertellini's insightful analysis of The Italian, which provides the basis for my own discussion, shows that this film was a turning point in the representation of Italian-Americans (Bertellini 2009, 212-235). In contrast to the films discussed above, The Italian features an important segment dedicated to the main characters' lives before their departure to America. The young gondolier Beppo (played by Beban) is in love with Annette, but her father opposes their marriage because Beppo cannot afford to buy a house. The young man then emigrates and, after one year, Annette re-unites with him. An important aspect differentiating this couple from 'typical' immigrants is the fact that, during the time they are apart, their romantic bond remains intact: such bond usually remained unrepresented or was depicted as necessarily short-lived as, once in the US, immigrants were expected to sever all connections to their homeland. In The Italian, however, Beppo and Annette's love is presented through parallel shots of the two lovers across the ocean (Bertellini 2009, 220). As soon as the two meet again in the US, they immediately get married and, with the birth of a son, the domestic idyll is created. Yet, in accordance with melodramatic conventions, their happiness is soon put under threat.

Through a series of misadventures, Beppo temporarily ends up in jail while trying to obtain pasteurised milk for his sick son, who eventually dies. It is this tragic event that provokes a temporary racial 'regression' in Beppo. Until this point, he is portrayed as a picturesque and naive character, but undoubtedly honest and morally grounded. However, in the span of time in which he attempts to get revenge for his son, 'his posture, carriage, and face are not normal: he has acquired beast-like features' (Bertellini 2009, 224). The racial shift is realised with a disguise and is related to the intrusion into a space coded as Other: Beppo dresses up as a peddler in order to sneak into the house of Corrigan, the rich politician who had him unjustly incarcerated. Here, the revengeful, irrational, violent Italian, with the corresponding physical posture and attitude, is nothing more than a fiction, a masquerade. 
Beban's performance in this segment must be interpreted in light of other aspects, internal and external to the film. The actor had an extraordinary ability to do 'racial impersonations'. Indeed, Beban published several articles in which he described his method and his quest for the ethnographic authenticity of his roles (Bertellini 2009, 228). Hence, he played racialised characters, but was clearly perceived by the audience as a white actor: the prologue and the epilogue of The Italian show Beban as himself, 'sporting an elegant evening robe, [...] an upper-middle-class book lover' (Bertellini 2009, 225). The juxtaposition of the 'authentic' Beban in the prologue and epilogue, and of his racial impersonation in the middle of the film, is an explicit testimony to his acting skill. In other words, it is a demonstration of a white man's ability to take on other identities without losing his original 'virtue'. The film repeatedly stresses Beban's talent, as he is often shown in close-ups or extreme close-ups so that the audience can carefully observe his expert crafting of facial expressions. This procedure, though, is quite ambiguous and it does not serve to reaffirm racial categories in an unproblematic way. Another effect of these shots, besides underlining Beban's abilities, is to create the conditions for spectatorial identification with the Italian-American character, a possibility often denied in previous melodramas. Moreover, Beban's interpretations in some way deconstructed previous representations of Italian-American characters: 'as performances that foregrounded, manipulated, and thus de-essentialized the stereotypical markers of racial identity, racial impersonations could "create a space for creative self-determination and agency"" (Browder 2000, 10, cited in Bertellini 2009, 213).

The relation between law, race and citizenship is also given a different twist in The Italian. In the early 1910s, films started to emphasise the possibilities of immigrants' self-improvement, and they gradually disregarded an ideological model that strictly focused on racial determinism. In the film Making an American Citizen (Alice Guy 1912), the new citizen is in fact 'made' as such throughout a learning process, and the adhesion to American laws and lifestyle prevails over racial categorisation or 'natural' predisposition. In The Italian, we find a particularly interesting caption coinciding with Beppo's redemption: the moment when he gives up on his revenge plans. The caption reads: 'at the eternal bedside of his baby, where hate, revenge and bitterness melt to nothing in the crucible of sorrow'. The word 'melt' brings to mind the metaphor of the melting pot: the idea that an action with strong racial connotations, such as revenge, could somehow 'melt to nothing' indicates a shift in the general attitude observed in previous films.

The novelty of The Italian can also be found in its use of lighting with regards to Beppo. One example is the long shot in which he, having just been robbed by two Italian criminals, lies on the floor in an alley of the Lower East Side. In contrast with the principle of general visibility of the action, this image treats the various characters in a very different way, and this difference takes on a new symbolism. Beppo is fully visible and he is caught in a beam of natural light, while the two escaping criminals only appear as shadows and their dark figures become muddled with the bars of a gate. This stark visual contrast recalls the images in the photographic reportage by Jacob Riis (1890) 'How the Other Half Lives: Studies among the Tenements of New York'. Riis' photographs of the immigrant neighbourhoods, according to Dyer (1997), utilised contrasts of light 'to underline the difference among the poor' (113) or, in other words, to establish moral and racial contrasts in visual terms. Later on, a similar symbolic pattern is repeated. When Beppo looks outside through the bars of his cellar window, the light that hits him is full of moral significance, in opposition to the darkness of the prison. The protagonist's face, captured by a close-up, is lit with a beautiful chiaroscuro. As Dyer (1997) writes, the chiaroscuro is a 'key feature of the representation of whiteness' insofar as it can 'discipline, organise and fix the image, suggesting the exercise of spirit over 
subject matter' (115). This is a remarkable instance of a visual strategy traditionally associated to white subjects, which is now applied to an Italian-American character. Together with the other features of the film discussed above, this choice ensures that audiences have a different perception of Beppo, a perception that contrasts with the Italian criminals of this and previous films. This time, additionally, the melodramatic narrative guarantees a strong emotional connection between him and the audience.

\section{Conclusions}

In this paper, I have provided a reading of selected cinematic melodramas portraying ItalianAmerican characters in the early twentieth century. The multiple factors that granted these characters the condition of whiteness, and simultaneously contributed to their racial Othering, are at the centre of this discussion. Relating these representations to the US social context and contemporary political discourses, I have attempted to show how in this period the racial positioning of Italian immigrants was complex, at times contradictory, and in transition. As scholars have argued both in the fields of sociology (Guglielmo and Salerno 2003) and film studies (Bertellini 2009), whiteness was not a permanent condition, but the result of ongoing power struggles. By focusing on how visual strategies, cultural stereotypes and legal discourses intertwined in the definition of whiteness, I have highlighted the constructedness of the racial categorisation of whiteness and how cinema represented it

I have suggested that cinema played an important role in shaping immigrants' self-perception within the new society, and that the film industry was aware of this. Whereas negative stereotypes about Italian-Americans were predominant, some films also provided positive models and promoted the identification of the audiences with them. This was made possible by the newly acquired centrality of the cinematic character. The transformations of US cinema in these same years allowed for a more nuanced representation of Italian-Americans. Narration became the driving force of films, supported by framing and editing techniques which clarified the details of the plot and guided the viewers' attention to the acting and its psychological implications. The differences between Griffith's films and Barker's The Italian entail not only the softening of racial stereotypes, but also the possibility of sharing the immigrant's emotions and points of view. Throughout this period, though, Italian-Americans' whiteness was not a guarantee of their full assimilation into US society. It remained, in the words of Jacobson (1998), a whiteness 'of a different colour'. The contested whiteness of these characters is representative of the contradictory experience of Italian-Americans, both as new members of American society and as spectators of a new and evolving medium.

By focusing on a context in which both racial categories and the dominant paradigms of cinema were rapidly changing, I hope that the issues raised in this article will also be relevant to scholars of contemporary media. As Arjun Appadurai (1996) argues, in recent decades media mutations and migration patterns are still closely interrelated. A diverse and rapidly changing mediascape facilitates movements of people across the globe, and it contributes to the negotiation of individual and collective identities in new societies. Media production and consumption, therefore, remain a highly charged terrain, in which racism is both sustained and contested. Against this backdrop, a methodological approach that combines reception studies, close-reading of media texts, and a historically grounded discussion of racialisation will provide effective tools for interpreting and contrasting new forms of Othering. 


\section{References}

Appadurai, A. (1996) Modernity at Large. Cultural Dimensions of Globalization, Minneapolis: University of Minnesota Press.

Baldwin, J. (1984) 'On Being "White”... and Other Lies', in D.A. Roediger (ed.) (1998) Black on White: Black Writers on What it Means to Be White, New York: Shocken Books (pp. 177-180).

Bernardi, D. (1996) 'The Voice of Whiteness. D.W. Griffith's Biograph Films (19081913)', in D. Bernardi (ed.) The Birth of Whiteness. Race and the Emergence of U.S. Cinema, New Brunswick: Rutgers (pp. 103-128).

Bertellini, G. (2004) 'Ethnic Self-Fashioning at the Cafè-Chantant. Southern Italian Immigrants, Vernacular Theater, and films in Pre-World War One New York, 19061916', in W. Boelhower and A. Scacchi (eds.) Public Space/Private Lives: Race, Gender, Class and Citizenship in New York, 1890-1929, Amsterdam: VU University Press (pp. 39-66).

Bertellini, G. (2009) Italy in Early American Cinema. Race, Landscape and the Picturesque, Bloomington: Indiana University Press.

Bhabha, H.K. (1994) 'The Other Question. Stereotype, Discrimination and the Discourse of Colonialism', in The Location of Culture, London: Routledge (pp. 6684).

Browder, L. (2000) Slippery Characters: Ethnic Impersonators and American Identities, Chapel Hill: University of North Carolina Press.

Butler, J. (1990) Gender Trouble. Feminism and the Subversion of Identity, London: Routledge.

Carluccio, G. (1999) Verso il primo piano. Attrazioni e racconto nel cinema americano 1908-1909: il caso Griffith-Biograph, Bologna: Clueb.

Dyer, R. (1997) White. Essays on Race and Culture, London: Routledge.

Gabaccia, D.R. (2003) 'Race, Nation, Hyphen: Italian-Americans and American Multiculturalism in Comparative Perspective', in J. Guglielmo and S. Salerno (eds.) Are Italians White? How Race is Made in America, London: Routledge (pp. 44-59).

Gaines, J. (1986) 'White Privilege and Looking Relations: Race and Gender in Feminist Film Theory', Cultural Critique, 4, Autumn, 59-79.

Gaines, J. (2001) Fire \& Desire. Mixed-Race Movies in the Silent Era, Chicago: University of Chicago Press.

Guglielmo, J. and Salerno, S. (eds.) (2003) Are Italians White? How Race is Made in America, London: Routledge. 
Gunning, T. (1991) D.W. Griffith and the Origins of American Narrative Film: The Early Years, Urbana and Chicago: University of Illinois Press.

Hall, S. (1992) 'Cultural Studies and its Theoretical Legacies', in D. Morley and K.H. Chen (eds.) (1996) Stuart Hall. Critical Dialogues in Cultural Studies, London: Routledge (pp. 261-274).

Hansen, M. (1991) Babel and Babylon. Spectatorship in American Silent Film, Cambridge: Harvard UP.

Hollinger, D.A. (2005) 'The One Drop Rule \& the One Hate Rule', Daedalus, Winter, 18-28.

Jacobson, M.F. (1998) Whiteness of a Different Color. European Immigrants and the Alchemy of Race, Cambridge: Harvard University Press.

Kaplan, E.A. (1997) Looking For the Other: Feminism, Film and the Imperial Gaze, London: Routledge.

Keil, C. (2001) Early American Cinema in Transition. Story, Style, and Filmmaking, 1907-1913, Madison: University of Wisconsin Press.

Mayne, J. (1988) Private Novels, Public Films, Athens: University of Georgia Press.

Mulvey, L. (1975) 'Visual Pleasure and Narrative Cinema', Screen, 16, 3, 16-18.

Muscio, G. (2004) Piccole Italie, Grandi Schermi. Scambi cinematografici tra Italia e Stati Uniti 1895-1945, Rome: Bulzoni.

Omi, M. and Winant, H. (2008) 'Once More, With Feeling: Reflections on Racial Formation', PMLA, 123, 5, 1565-1572.

Pearson, R.E. (1992) Eloquent Gestures. The Transformation of Performance Style in the Griffith Biograph Films, Berkeley: University of California Press.

Riis, J.A. (2009)[1890] How the Other Half Lives: Studies among the Tenements of New York, USA: CreateSpace.

Roediger, D.R. (1991) The Wages of Whiteness. Race and the Making of the American Working Class, London: Verso.

Singer, B. (2001) Melodrama and Modernity. Early Sensational Cinema and its Contexts, New York: Columbia University Press.

Stokes, M. (2007) D. W. Griffith's The Birth of a Nation: A History of 'The Most Controversial Motion Picture of All Time', New York: Oxford University Press.

Uricchio, W. (1999) 'La formazione del pubblico. L'audience ai tempi dei nickelodeon', in Brunetta, G.P. (ed.) Storia del cinema mondiale. Vol 2.1. Gli Stati Uniti, Turin: Einaudi (pp. 175-198). 
Wiegman, R. (1999) 'Whiteness Studies and the Paradox of Particularity', Boundary 2, 26, 3, 115-150.

\section{Biography}

Valerio Coladonato obtained a PhD in Film Studies at the University of Rome "La Sapienza", with a thesis on masculinities in contemporary cinema. He has published several essays in Italian and international journals, focusing on gender, and the reception and analysis of films. His research interests also include stardom in the Italian context, and the relationship between cinema, politics and new media. He can be contacted at valerio.coladonato@ gmail.com 